Journal of Applied Mathematics and Simulation Vol. 1, Issue 1, 1987.

\title{
ON A MULTI-CHANNEL TRANSPORTATION LOSS SYSTEM WITH CONTROLLED INPUT AND CONTROLLED SERVICE
}

\author{
JEWGENI DSHALALOW \\ University of Pittsburgh at Bradford \\ Campus Drive \\ Bradford, PA 16701
}

\begin{abstract}
A multi-channel loss queueing system is investigated. The input stream is a controlled point process. The service in each of $\mathrm{m}$ parallel channels depends on the state of the system at certain moments of time when input and service may be controlled. To obtain explicitly the limiting distribution of the main process $\left(Z_{t}\right)$ (the number of busy channels) in equilibrium, an auxiliary three dimensional process with two additional components (one of them is a semi-Markov process) is treated as semi-regenerative process. An optimization problem is discussed. Simple expressions for an objective function are derived.
\end{abstract}

Key words: multi-channel queue, controlled process, limiting distribution, semi-Markov process, semi-regenerative process, optimization

AMS subject classification: 60K25, 90B22

\section{INTRODUCTION}

The loss queueing models were originally used to describe the first telephone communication systems. Any such system was equipped with finite many lines, and every new call entering the system was immediately lost if all lines were busy. In the general telephone communication model the input stream of calls formed an arbitrary renewal process, and the telephone call durations in each of the lines were exponentially distributed. These models were completely investigated by Takács [3] in his classical work. We could attempt making similar systems more flexible, for instance, by governing the input stream of calls and even their "servicing process."

Technological perfection provides wide possibilities to control stochastic systems and does so in such a way to considerably improve their effectiveness. One can give plenty of examples occuring in real life (telephone communication systems, computer systems, airports, hospitals) where such a control is a real consideration. However, we restrict ourselves to conceivably the most descriptive model - a transportation system.

Suppose that the vehicles loaded with a raw material depart a production center and move towards a certain storehouse. Upon arrival of a vehicle the material delivered is 
deposited in a storage unit for the redistribution. The material is shipped (in lots) until the storage unit becomes free again. Suppose that the number of units available is $\mathrm{m}$. If all storage units are busy upon arrival of the delivery vehicle the product cannot be stored (it is perishable) and thus is certainly lost for the system. Elimination or reduction of such loss becomes extremely important. In many storehouses a penalty is paid not only for inability to store a product, but also for storing it in alternative locations. On the other hand it is undesirable to have a large number of idle storage units. Such a system can be optimized in several ways:

1) If the vehicles deliver the goods to several consumption points then it is worthwhile to choose a "longer" route if the store is overstocked.

2) In some cases a scheduler can decide not to send any vehicle at all until the store has sufficient storage for new inventory.

3) The store can also attempt to intensify the service (for instance, additional promotions or advertisements).

To arrive at an optimal policy is an important task, specifically under the above cost considerations.

The model above can be formalized as follows.

Let $\mathrm{Z}_{\mathrm{t}}$ be the number of storage units occupied by the goods at a time $t(\geq 0)$. There are exactly $m$ storage units in the system. The $n$th vehicle departs the base at time $T_{n}$ and arrives in the store at time $T_{n+1}$. We assume that $T_{n+1}-T_{n}$ is distributed in accordance with the distribution function (DF) $A_{x_{n}} \in\left\{A_{0}(x), A_{1}(x), \ldots, A_{m}(x)\right\}$, where $X_{n}:=Z_{T_{n}-}$, $\mathrm{n}=0,1, \ldots, \mathrm{A}_{\mathrm{k}}(\mathrm{x})$ is an arbitrary DF with $\mathrm{A}_{\mathrm{k}}(0+)=0, \mathrm{~A}_{\mathrm{k}}(+\infty)=1$ and $0<\mathrm{a}_{\mathrm{k}}:=\int_{\mathbb{R}_{+}} \mathrm{xA}_{\mathrm{k}}(\mathrm{dx})<\infty, \mathrm{k}=0,1, \ldots, \mathrm{m}$. Within the interval $\left[\mathrm{T}_{\mathrm{n}}, \mathrm{T}_{\mathrm{n}+1}\right)$ the storage

durations of all goods are conditionally independent given $X_{n}$ and exponentially distributed with parameter $\mu_{\mathrm{x}_{\mathrm{n}}} \in\left\{\mu_{0}, \mu_{1}, \ldots, \mu_{\mathrm{m}}\right\}, 0<\mu_{\mathrm{k}}<\infty$.

In Section 3 we are concerned with the embedded process $\left(X_{n}\right)$ and for a special case derive explicitly the limiting distribution of $\left(X_{n}\right)$. Among many applications a reliability system is introduced, which appears dual with our transportation model. In Section 4 we treat the main process $\left(Z_{t}\right)$ with continuous time parameter and find explicitly its limiting distribution by introducing a three-dimensional Markov process. To solve the corresponding Kolmogorov differential equations we use a similar method developed in Dshalalow [2] and apply the main convergence theorem for semi-regenerative processes. An example of an optimization problem of general type is given. This demonstrates the advantages of the results obtained. 


\section{NOTATION}

In this section we give some more notation required in the remainder of the paper:

$$
\begin{aligned}
& \alpha_{j}(\theta):=\int_{\mathbb{R}_{+}} e^{-\theta x} A_{j}(d x), \operatorname{Re}(\theta) \geq 0, \alpha_{r}^{j}:=\alpha_{j}\left(r \mu_{j}\right), \\
& d_{r}^{j}:=\left\{\begin{array}{c}
1, \quad r=0 \\
\prod_{i=0}^{r} \frac{\alpha_{i}^{j}}{1-\alpha_{i}^{j}}, r=1, \ldots, m
\end{array}\right. \\
& \Delta_{j k}^{r}:=\left\{\begin{array}{c}
\sum_{i=k+1}^{i}(-1)^{j-1}\left(\begin{array}{l}
i \\
r
\end{array}\right)\left(\begin{array}{l}
j \\
r
\end{array}\right), k=0,1, \ldots, j-1 \\
0 \quad k=j, \ldots, m \quad 0 \leq r \leq i \leq j, j=0,1, \ldots, m .
\end{array}\right.
\end{aligned}
$$

In case if $\mathrm{A}(\mathrm{x})$ (a, respectively) and $\mu$ do not possess any index we omit the superscripts in $\alpha_{r}^{j}$ and $d_{r}^{j}$ as $\alpha_{r}$ and $d_{r}$. Let

$$
b_{j}:=\sum_{n=j}^{m} \frac{\left(\begin{array}{l}
m \\
n
\end{array}\right)}{d_{n}}
$$

Finally, we define the operators $R_{k}$ on $\mathbb{C}_{\mathbb{R}}^{(k)}$ by

$$
\mathrm{R}_{\mathrm{k}} \mathrm{f}:=\frac{1}{\mathrm{k} !} \lim _{\mathrm{z} \uparrow 1} \frac{\mathrm{d}^{\mathrm{k}}}{\mathrm{dz}^{\mathrm{k}}} \mathrm{f}(\mathrm{z}), \mathrm{f} \in \mathbb{C}_{\mathbb{R}}^{(\mathrm{k})}, \mathrm{k}=0,1, \ldots, \mathrm{m} .
$$

\section{EMBEDDED PROCESS}

It is readily seen that

$\left(\left(\mathrm{P}^{\mathrm{x}}\right)_{\mathrm{x} \in \mathrm{E}},\left\{\mathrm{X}_{\mathrm{n}} ; \mathrm{n}=0,1, \ldots, \mathrm{m}\right\}\right) \rightarrow \mathrm{E}=\{0,1, \ldots, \mathrm{m}\}$

is a homogeneous irreducible and aperiodic Markov chain (MC) embedded in $\left(\left(P^{x}\right)_{x \in E},\left\{Z_{t} ; t \geq 0\right\}\right) \rightarrow E$ over the moments $T_{0}, T_{1}, \ldots$

with transition probability matrix 
where

$$
\mathrm{M}=\left[\begin{array}{cccccc}
\mathrm{p}_{00} & \mathrm{p}_{01} & 0 & 0 & \ldots & 0 \\
\mathrm{p}_{10} & \mathrm{p}_{11} & \mathrm{p}_{12} & 0 & \ldots & 0 \\
\ldots & \ldots & \ldots & \ldots & \ldots & \ldots \\
\mathrm{p}_{\mathrm{m} 0} & \mathrm{p}_{\mathrm{m} 1} & \mathrm{p}_{\mathrm{m} 2} & \ldots & \ldots & \mathrm{p}_{\mathrm{mm}}
\end{array}\right]
$$

$$
p_{j k}=\int_{\mathbb{R}_{+}}\left(\begin{array}{c}
i_{j} \\
k
\end{array}\right) e^{-k \mu_{j} t}\left(1-e^{-\mu_{j} t}\right)^{i_{j}-k} A_{j}(d t), \quad \begin{aligned}
& k=0,1, \ldots, j+1, j=0, \ldots, m, i_{j}=j+1, \\
& j=0,1, \ldots m-1, i_{j}=m, j=m
\end{aligned}
$$

Therefore, the $\mathrm{MC}\left(\mathrm{X}_{\mathrm{n}}\right)$ is recurrent-positive and there exists an invariant probability measure $\mathbf{P}=\left(\mathrm{P}_{0}, \mathrm{P}_{1}, \ldots, \mathrm{P}_{\mathrm{m}}\right)$ of $\left(\mathrm{X}_{\mathrm{n}}\right)$ as a unique positive solution of the matrix equation

$$
\left\{\begin{array}{c}
\mathbf{x}=\mathbf{x M} \\
\mathbf{x} \mathbf{1}=1, \mathbf{x} \in \mathbb{R}^{\mathrm{E}}
\end{array}\right.
$$

From (3.2) we easily obtain an equation of $\mathbf{P}$ and of its generating function $\mathrm{P}(\mathrm{z})$ :

$$
P(z)=\sum_{i=0}^{m} P_{i} z^{i}=\sum_{j=0}^{m} P_{j} \int\left(1-e_{\mathbb{R}_{+}}^{-\mu_{j} x}+z e^{-\mu_{j} x}\right)^{j+1} A_{j}(d x)+(1-z) P_{m} \int_{\mathbb{R}_{+}}\left(1-e^{-\mu_{m} x}+z e^{-\mu_{m} x}\right)^{m} A_{m}(d x) .
$$

Because the system (3.2) is finite the solution of (3.2) can be derived directly by using standard computational algorithms. To find the solution of (3.2) explicitly we assume that

$$
\begin{gathered}
A_{j}(x)= \begin{cases}A_{k}(x), & j=0,1, \ldots, k \\
A_{s}(x), & j=k+1, \ldots, s \\
A(x), & j=s+1, \ldots, m\end{cases} \\
\mu_{j}= \begin{cases}\mu_{k}, & j=0,1, \ldots, k \\
\mu_{s}, & j=k+1, \ldots, s \\
\mu, & j=s+1, \ldots, m\end{cases}
\end{gathered}
$$

and call such model the system with two control levels. Without this restriction the general model is therefore the system with m control levels.

3.1 Theorem. For the transportation system with input and servicing process defined by (3.4) and (3.4a) the invariant probability measure $\mathbf{P}$ of $\left(\mathrm{X}_{\mathrm{n}}\right)$ is given by the following formulas: 


$$
\begin{aligned}
& P_{i}=c \sum_{j=i}^{k}(-1)^{j-i}\left(\begin{array}{l}
j \\
i
\end{array}\right) \tilde{E}_{k j}, \quad i=0,1, \ldots, k \\
& P_{i}=c \sum_{j=i}^{s}(-1)^{j-i}\left(\begin{array}{l}
j \\
i
\end{array}\right) \tilde{E}_{s j}, \quad i=k+1, \ldots, s \\
& P_{i}=c \sum_{j=i}^{m}(-1)^{j-i}\left(\begin{array}{l}
j \\
i
\end{array}\right) \tilde{B}_{j}, \quad i=s+1, \ldots, m,
\end{aligned}
$$

where

$\tilde{\mathrm{E}}_{\mathrm{kj}}, \tilde{\mathrm{E}}_{\mathrm{sj}}, \tilde{\mathrm{B}}_{\mathrm{j}}$ and $\mathrm{c}$ are determined in (3.16), (3.18-3.22) below.

Proof: Applying the operator $\mathrm{R}_{\mathrm{r}}$ (see Notation) to both sides of (3.3) we obtain the system of linear equations

$$
\mathrm{E}_{\mathrm{kr}}=\alpha_{\mathrm{r}}^{\mathrm{k}}\left(\mathrm{E}_{\mathrm{kr}}+\mathrm{E}_{\mathrm{k}, \mathrm{r}-1}\right)-\mathrm{W}_{\mathrm{r}}, \quad \mathrm{r}=1,2, \ldots, \mathrm{m}
$$

where

$$
\text { (3.9) } E_{p r}:=\left\{\begin{array}{cc}
\sum_{j=r}^{p}\left(\begin{array}{l}
j \\
r
\end{array}\right) P_{j}, & r=0,1, \ldots, p \\
0, & r=p+1, \ldots, m
\end{array}\right.
$$

(3.10) $\mathrm{W}_{\mathrm{r}}:=\left(1-\alpha_{\mathrm{r}}^{\mathrm{s}}\right) \mathrm{F}_{\mathrm{ksr}}-\alpha_{\mathrm{r}}^{\mathrm{s}} \mathrm{F}_{\mathrm{ks}, \mathrm{r}-1}+\left(1-\alpha_{\mathrm{r}}\right) \mathrm{B}_{\mathrm{sr}}-\alpha_{\mathrm{r}} \mathrm{B}_{\mathrm{s}, \mathrm{r}-1}+\alpha_{\mathrm{r}} \mathrm{B}_{\mathrm{m}}\left(\begin{array}{l}\mathrm{m} \\ \mathrm{r}-1\end{array}\right)$

(3.11) $F_{k s r}:=\left\{\begin{array}{cl}\sum_{j=k+1}^{m} P_{j}\left(\begin{array}{l}j \\ r\end{array}\right), & r=0,1, \ldots, k+1 \\ E_{s r} & r=k+1, \ldots, s \\ 0 & , r=s+1, \ldots, m\end{array}\right.$

(3.12) $B_{s r}:=\left\{\begin{array}{cc}\sum_{j=s+1}^{m}\left(\begin{array}{l}j \\ r\end{array}\right) P_{j}, & r=0,1, \ldots, s+1 \\ B_{r}, & r=s+1, \ldots, m\end{array}\right.$

(3.13) $B_{r}:=\sum_{j=r}^{m}\left(\begin{array}{l}j \\ r\end{array}\right) P_{j}, \quad r=0, \ldots, m$

For $A_{k}(x)=A_{s}(x)$ and $\mu_{k}=\mu_{s}(3.8)$ is reduced to 
(3.14) $\mathrm{E}_{\mathrm{sr}}=\alpha_{\mathrm{r}}^{\mathrm{s}}\left(\mathrm{E}_{\mathrm{sr}}+\mathrm{E}_{\mathrm{sr}-1}\right)-\mathrm{W}_{\mathrm{r}}, \quad \mathrm{r}=1, \ldots, \mathrm{m}$,

where (in $\mathrm{W}_{\mathrm{r}}$ ) we set $\mathrm{F}_{\mathrm{ksr}}=0, \mathrm{r}=0,1, \ldots, \mathrm{m}$. For $\mathrm{A}_{\mathrm{i}}(\mathrm{x})=\mathrm{A}(\mathrm{x}), \mu_{\mathrm{i}}=\mu, \mathrm{i}=0,1, \ldots, \mathrm{m}$, (3.14) can further be simplified as

(3.15) $\mathrm{B}_{\mathrm{r}}=\alpha_{\mathrm{r}}\left(\mathrm{B}_{\mathrm{r}}+\mathrm{B}_{\mathrm{r}-1}-\left(\begin{array}{c}\mathrm{m} \\ \mathrm{r}-1\end{array}\right) \mathrm{B}_{\mathrm{m}}\right), \mathrm{r}=1, \ldots, \mathrm{m}\left(\mathrm{B}_{\mathrm{m}}=\mathrm{P}_{\mathrm{m}}\right)$.

The solution of (3.15) (i.e. for the model GI/M/m/0) was given in Takács [3], p.179, in the form

$\tilde{B}_{j}=d_{j} \frac{b_{j}}{b_{0}}, j=0,1, \ldots, m$ (see Notation).

(3.8) and (3.14) have the same shape as (3.15) for $r=s+2, \ldots, m$. Hence, we conclude that $B_{r}, r=s+1, \ldots, m$, from (3.14) and (3.15) can differ only in a positive real multiplicator $\mathrm{c}$, i.e.

(3.16) $\mathrm{B}_{\mathrm{r}}=\mathrm{c} \tilde{\mathrm{B}}_{\mathrm{r}}=\mathrm{cd}_{\mathrm{r}} \frac{\mathrm{b}_{\mathrm{r}}}{\mathrm{b}_{0}}, \mathrm{r}=\mathrm{s}+1, \ldots, \mathrm{m}$.

By notation

$\tilde{\mathrm{W}}_{\mathrm{r}}:=\mathrm{c}^{-1} \mathrm{~W}_{\mathrm{r}}, \tilde{\mathrm{B}}_{\mathrm{sr}}:=\mathrm{c}^{-1} \mathrm{~B}_{\mathrm{sr}}, \tilde{\mathrm{E}}_{\mathrm{sr}}:=\mathrm{c}^{-1} \mathrm{E}_{\mathrm{sr}}, \quad \mathrm{r}=1, \ldots, \mathrm{m}$,

we obtain from (3.15)

(3.17) $\tilde{\mathrm{E}}_{\mathrm{sr}}=\alpha_{\mathrm{r}}^{\mathrm{s}}\left(\tilde{\mathrm{E}}_{\mathrm{sr}}+\tilde{\mathrm{E}}_{\mathrm{sr}-1}\right)-\tilde{\mathrm{W}}_{\mathrm{r}}, \quad \mathrm{r}=1, \ldots, \mathrm{m}$.

(3.17) can be solved by a recursive procedure

(3.18) $\tilde{E}_{s n}=d_{n}^{s} \sum_{r=n}^{s} \frac{\tilde{W}_{r+1}}{\alpha_{r+1}^{s} d_{r}^{s}}$

$$
=d_{n}^{s} \sum_{r=n}^{s} \frac{\left(1-\alpha_{r+1}\right) \tilde{B}_{s r+1}+\alpha_{r+1}\left[\left(\begin{array}{l}
m \\
r
\end{array}\right) \tilde{B}_{m}-\tilde{B}_{s r}\right]}{\alpha_{r+1}^{s} d_{r}^{s}}, n=0,1, \ldots, s,
$$

with a simple formula for $\tilde{\mathrm{B}}_{\mathrm{sr}}$ given by

$$
\tilde{B}_{s r}=\sum_{j=s+1}^{m} d_{j} \Delta_{j s}^{r}, \quad r=0,1, \ldots, m .
$$

Using the same algorithm for the case (3.4), (3.4a) we obtain 
(3.20)

$$
\tilde{E}_{k n}=d_{n}^{k} \sum_{r=n}^{k} \frac{\left(1-\alpha_{r+1}^{s}\right) \tilde{F}_{k s, r+1} \alpha_{r+1}^{s} \tilde{F}_{k s r}+\left(1-\alpha_{r+1}\right) \tilde{B}_{s r+1}+\alpha_{r+1}\left[\left(\begin{array}{l}
m \\
r
\end{array}\right) \tilde{B}_{m}-\tilde{B}_{s r}\right]}{\alpha_{r+1}^{k} d_{r}^{k}}, n=0,1, \ldots, k
$$

where

$$
\tilde{\mathrm{F}}_{\mathrm{ksr}}=\mathrm{c}^{-1} \mathrm{~F}_{\mathrm{ksr}}=\mathrm{c}^{-1} \sum_{\mathrm{j}=\mathrm{k}+1}^{\mathrm{s}} \tilde{\mathrm{E}}_{\mathrm{sj}} \Delta_{\mathrm{jk}}^{\mathrm{r}}, \mathrm{r}=0,1, \ldots, \mathrm{k}+1 .
$$

Finally, $\mathrm{c}$ is to be derived from $(\mathbf{P}, \mathbf{1})=1$ :

$$
\mathrm{c}^{-1}=\tilde{\mathrm{E}}_{\mathrm{k} 0}+\tilde{\mathrm{F}}_{\mathrm{ks} 0}+\tilde{\mathrm{B}}_{\mathrm{s} 0} \text {. }
$$

Since $\mathrm{E}_{\mathrm{kn}}=\mathrm{c} \tilde{\mathrm{E}}_{\mathrm{kn}}, \mathrm{E}_{\mathrm{sn}}=\mathrm{c} \tilde{\mathrm{E}}_{\mathrm{sn}}$ and $\mathrm{B}_{\mathrm{r}}=\mathrm{c} \tilde{\mathrm{B}}_{\mathrm{r}}$ are the binomial moments of the corresponding generating functions $\sum_{\mathrm{i}=0}^{\mathrm{k}} \mathrm{P}_{\mathrm{i}} \mathrm{z}^{\mathrm{i}}, \sum_{\mathrm{i}=0}^{\mathrm{s}} \mathrm{P}_{\mathrm{i}} \mathrm{z}^{\mathrm{i}}$ and $\mathrm{P}(\mathrm{z})$, we can easily find the probabilities $\mathrm{P}_{0}, \mathrm{P}_{1}, \ldots, \mathrm{P}_{\mathrm{m}}$ by the formulas (3.5-3.7). That proves Theorem 3.1.

3.2 Remark. We obtained the results for two control levels where the input and the service change their rates concurrently. By setting $A_{k}(x)=A_{s}(x)$ and $\mu_{s}=\mu$ we bring the input and the service in two different levels allowing then the scheduler and the depot to make their decisions separately. In this case they may pursue their own interests.

3.3 Remark. Consider the following example of a reliability system. Suppose that there are $m+1$ machines working continuously and serviced by a single repairman. At any time each of the machines may break down independently from other ones. They are serviced by the repairman in the order of their falling out. The machines unfit for work form a waiting line. Let $W_{t}$ be the number of working machines at any time $t(\geq 0)$. The intensity of work being performed by every machine and the intensity of the repair time depends on the number of current intact machines at the moment of decision making. The decision points are the subsequent starts of machines repairs, say $t_{0}, t_{1}, \ldots$. We assume that the working duration of each functioning machine in the time interval $\left[t_{n}, t_{n+1}\right)$ is

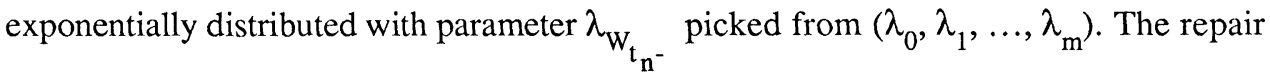
of the $\mathrm{n}^{\text {th }}$ machine starts at $\mathrm{t}_{\mathrm{n}}$ and requires a time distributed according to $\mathrm{B}_{\mathrm{W}_{\mathrm{t}^{-}}}(\mathrm{x}) \in\left\{\mathrm{B}_{0}(\mathrm{x}), \mathrm{B}_{1}(\mathrm{x}), \ldots, \mathrm{B}_{\mathrm{m}}(\mathrm{x})\right\}$, where $\mathrm{B}_{\mathrm{i}}(\mathrm{x})$ are arbitrary DF's. Let $\xi_{\mathrm{n}}:=\mathrm{W}_{\mathrm{t}_{\mathrm{n}}-}$, $\mathrm{n}=0,1, \ldots$. It is easily seen that $\left(\left(\mathrm{P}^{\mathrm{y}}\right)_{\mathrm{y} \in \mathrm{E}},\left(\xi_{\mathrm{n}} ; \mathrm{n}=0,1, \ldots\right)\right) \rightarrow \mathrm{E}=\{0,1, \ldots, \mathrm{m}\}$ is a $\mathrm{MC}$ embedded in $\left(\left(\mathrm{P}^{\mathrm{y}}\right)_{\mathrm{y} \in \mathrm{E}^{\prime}},\left(\mathrm{W}_{\mathrm{t}} ; \mathrm{t} \geq 0\right)\right) \rightarrow \mathrm{E}^{\prime}:=\{0,1, \ldots, \mathrm{m}+1\}$.

This reliability system is somewhat dual with the model investigated above. By assuming that $\mathrm{B}_{\mathrm{i}}(\mathrm{x})=\mathrm{A}_{\mathrm{i}}(\mathrm{x})$ and $\lambda_{\mathrm{i}}=\mu_{\mathrm{i}}, \mathrm{i}=0,1, \ldots, \mathrm{m}$, one can readily see that the transition 
probability matrices of both $M C$ 's $\left(X_{n}\right)$ and $\left(\xi_{r}\right)$ coinside, specifically because $\left.P m_{\left\{X_{1} \in C\right.}\right\}$ $=\mathrm{Pm}\left\{\xi_{1} \in \mathrm{C}\right\}, \mathrm{C} \subset \mathrm{E}$, i.e. the exponentially distributed idleness of the repairman in case of reliability system does not affect the values of the corresponding transition probabilities. Therefore, the results for the transportation system obtained above can be completely adopted for the given reliability model with controlled intensity of machine work and repair.

We observe that without assumptions on the control the given reliability model belongs to a classical one investigated by Takács [3], pp. 189-204. However, Takács obtained results for the process $\left(\mathrm{W}_{\mathrm{t}}\right)$ with continuous time parameter. A similar reliability system of general type with a number of reserve machines was found for the first time in Dshalalow [2] but without control over intensity of machine work.

\section{PROCESS $\left(\mathrm{Z}_{t}\right)$}

It is readily seen that the times $T_{0}, T_{1}, \ldots$ of successive departures of the vehicles are the moments of Markov regeneration of the process $\left(\mathrm{Z}_{t}\right)$. Therefore, $\left(\mathrm{Z}_{t}\right)$ is a semiregenerative process relative to $\left\{T_{n}\right\}$ (see Definition A.1, Appendix). Let $(X, T):=$ $\left(X_{n}, T_{n} ; n=0,1, \ldots\right)$ be the associated Markov renewal process embedded in $\left(Z_{t}\right)$. It is obviously aperiodic and (due to Cinlar [1], p. 322) recurrent-positive. This provides the existance of the limiting distribution $\boldsymbol{\pi}=\left(\pi_{0}, \pi_{1}, \ldots, \pi_{\mathrm{m}}\right)$ of $\left(\mathrm{Z}_{\mathrm{t}}\right)$ by the mean convergence theorem (see Theorem A.2, Appendix). To derive $\pi$ explicitly we introduce an auxiliary process (that is also of independent interest). Let $\left(\mathrm{N}_{t}\right)$ be the counting process associated with the point process $\left(\mathrm{T}_{\mathrm{n}}\right)$ and let $\mathrm{Y}_{\mathrm{t}}:=\mathrm{A}_{\mathrm{T}_{\mathrm{N}_{\mathrm{t}}-}}, \mathrm{V}_{\mathrm{t}}:=\mathrm{T}_{\mathrm{N}_{\mathrm{t}^{+1}}}$-t.

We observe that the process $\left\{V_{t} ; t \geq 0\right\}$ describes the residual time from $t$ to the next arrival, and $\left\{Y_{t} ; t \geq 0\right\}$ is the embedded semi-Markov process associated with $(X, T)$. It is easily seen that

$$
\left(\Omega, \mathscr{A},\left(\mathrm{P}^{\mathrm{x}}\right)_{\mathrm{x} \in \mathrm{E}},\left(\mathrm{Y}_{\mathrm{t}}, \mathrm{Z}_{\mathrm{t}}, \mathrm{V}_{\mathrm{t}}: \mathrm{t} \geq 0\right)\right) \rightarrow(\mathscr{E}, \mathscr{B}(\mathscr{E})), \mathscr{E}:=\mathrm{E} \times \mathrm{E} \times \mathbb{R}_{+}
$$

( $\mathscr{B}(\mathscr{E})$ is Borel $\sigma$-algebra), is a homogeneous Markov process with transition function

$\mathrm{P}_{\mathrm{t}}(\mathrm{i}, \mathrm{B})=\mathrm{P}^{\mathrm{i}}\left\{\left(\mathrm{Y}_{\mathrm{t}}, \mathrm{Z}_{\mathrm{t}} \mathrm{V}_{\mathrm{t}}\right) \in \mathrm{B}\right\}, \mathrm{i} \in \mathrm{E}, \mathrm{B} \in \mathscr{B}(\mathscr{E})$,

which is supposed to possess a transition density

$\pi_{j k}^{i}(u, t) d u=P^{i}\left\{Y_{t}=j, Z_{t} \in(u, u+d u]\right\}, i, j, k \in E, u \in \mathbb{R}_{+}$,

with existing first partial derivatives. Throughout the remainder of this paper we will also assume that $\mathrm{A}_{\mathrm{i}}(\mathrm{x})$ is absolutely continuous and its density $\mathrm{a}_{\mathrm{i}}(\mathrm{x})$ is pointwise continuous, $\mathrm{i}=0,1, \ldots, \mathrm{m}$. Under these assumptions and notations the following main result of this section holds.

4.1 Theorem. The limiting distribution $\pi$ of the process $\left(\mathrm{Z}_{\mathrm{t}}\right)$ exists and satisfies the following formulas: 
(4.1) PAn $\pi_{n}=\sum_{k=0}^{n-1} \sum_{j=k-1}^{m} \frac{\left(1-\delta_{j,-1}\right) P_{j} p_{j k}}{\mu_{j}}-\left(1-\delta_{n, 1}\right) \sum_{k=1}^{n-1} \frac{P_{k-1}}{\mu_{k-1}}, n=1, \ldots, m$,

$$
\pi_{0}=1-\sum_{n=1}^{m} \pi_{n}
$$

where $\delta$ is Kronecker delta, $\mathrm{p}_{\mathrm{jk}}, \mathrm{j}, \mathrm{k} \in \mathrm{E}$, are transition probabilities of $\left(\mathrm{X}_{\mathrm{n}}\right), \mathbf{P A}$ is scalar product of $\mathbf{P}=\left(\mathrm{P}_{0}, \mathrm{P}_{1}, \ldots, \mathrm{P}_{\mathrm{m}}\right)$ and $\mathbf{A}=\left(\mathrm{a}_{0}, \mathrm{a}_{1}, \ldots, \mathrm{a}_{\mathrm{m}}\right)^{\mathrm{T}}$ (see Notation).

Proof: Since we shall deal with the limiting distribution of the process $\left(\mathrm{Y}_{\mathrm{t}}, \mathrm{Z}_{\mathrm{t}}, \mathrm{V}_{\mathrm{t}}\right)$ we drop the superscript $i$ in $\pi_{j k}^{i}(u, t)$. The Kolmogorov differential equations for $\pi_{j k}(u, t)$ are as follows:

$$
\begin{aligned}
& \text { (4.3) }\left(\frac{\partial}{\partial \mathrm{t}}-\frac{\partial}{\partial \mathrm{u}}\right) \pi_{\mathrm{jk}}(\mathrm{u}, \mathrm{t})=-\mathrm{k} \mu_{\mathrm{j}} \pi_{\mathrm{jk}}(\mathrm{u}, \mathrm{t})+(\mathrm{k}+1) \mu_{\mathrm{j}} \pi_{\mathrm{jk}+1}(\mathrm{u}, \mathrm{t}), 0 \leq \mathrm{k} \leq \min (\mathrm{j}, \mathrm{m}-1), 0 \leq \mathrm{j} \leq \mathrm{m}, \\
& \text { (4.4) }\left(\frac{\partial}{\partial \mathrm{t}}-\frac{\partial}{\partial \mathrm{u}}\right) \pi_{\mathrm{k}-1, \mathrm{k}}(\mathrm{u}, \mathrm{t})=-\mathrm{k} \mu_{\mathrm{k}-1} \pi_{\mathrm{k}-1, \mathrm{k}}(\mathrm{u}, \mathrm{t})+\pi_{\mathrm{k}-1}(0, \mathrm{t}) \mathrm{a}_{\mathrm{k}-1}(\mathrm{u}), \mathrm{j}=\mathrm{k}-1, \ldots, \mathrm{m}, \\
& \text { (4.5) }\left(\frac{\partial}{\partial \mathrm{t}}-\frac{\partial}{\partial \mathrm{u}}\right) \pi_{\mathrm{mm}}(\mathrm{u}, \mathrm{t})=-\mathrm{m} \mu_{\mathrm{m}} \pi_{\mathrm{mm}}(\mathrm{u}, \mathrm{t})+\pi_{\mathrm{m}}(0, \mathrm{t}) \mathrm{a}_{\mathrm{m}}(\mathrm{u}), \mathrm{k}=\mathrm{j}=\mathrm{m},
\end{aligned}
$$

where $\pi_{\mathrm{k}}(\mathrm{u}, \mathrm{t})$ denotes the density for the corresponding marginal process $\left(\mathrm{Z}_{\mathrm{t}}, \mathrm{V}_{\mathrm{t}}\right)$. Let

$$
\begin{aligned}
& \pi_{\mathrm{jk}}(\mathrm{u}):=\lim _{\mathrm{t} \rightarrow \infty} \pi_{\mathrm{jk}}(\mathrm{u}, \mathrm{t}), \pi_{\mathrm{k}}(\mathrm{u}):=\lim _{\mathrm{t} \rightarrow \infty} \pi_{\mathrm{k}}(\mathrm{u}, \mathrm{t}) \text { and } \\
& \tilde{\pi}_{\mathrm{jk}}(\theta):=\int_{\mathbb{R}_{+}} \pi_{\mathrm{jk}}(\mathrm{u}) \mathrm{e}^{-\theta \mathrm{u}} \mathrm{du}, \Re \mathrm{R}(\theta) \geq 0, \mathrm{j}, \mathrm{k} \in \mathrm{E} .
\end{aligned}
$$

Now letting $t \rightarrow \infty$ in (4.3-4.5) and then applying the Laplace operator to the equations obtained, we have

$$
\begin{aligned}
& \left(\theta-\mathrm{k} \mu_{\mathrm{j}}\right) \tilde{\pi}_{\mathrm{jk}}(\theta)=\pi_{\mathrm{jk}}(0)=\pi_{\mathrm{jk}}(0)-(\mathrm{k}+1) \mu_{\mathrm{j}} \tilde{\pi}_{\mathrm{j}, \mathrm{k}+1}(\theta), 0 \leq \mathrm{k} \leq \min (\mathrm{j}, \mathrm{m}-1), 0 \leq \mathrm{j} \leq \mathrm{m}, \\
& \left(\theta-\mathrm{k} \mu_{\mathrm{k}-1}\right) \tilde{\pi}_{\mathrm{k}-1, \mathrm{k}}(\theta)=\pi_{\mathrm{k}-1, \mathrm{k}}(0)-\pi_{\mathrm{k}-1}(0) \alpha_{\mathrm{k}-1}(\theta), \mathrm{j}=\mathrm{k}-1, \mathrm{k}=1, \ldots, \mathrm{m}, \\
& \left(\theta-\mathrm{m} \mu_{\mathrm{m}}\right) \tilde{\pi}_{\mathrm{mm}}(\theta)=\pi_{\mathrm{mm}}(0)-\pi_{\mathrm{m}}(0) \alpha_{\mathrm{m}}(\theta), \mathrm{j}=\mathrm{k}=\mathrm{m} .
\end{aligned}
$$

For $\theta \downarrow 0$ in (4.6-4.8) and by notation $\pi_{\mathrm{jk}}:=\lim _{\theta \downarrow 0} \tilde{\pi}_{\mathrm{jk}}(\theta)=\int_{\mathbb{R}_{+}} \pi_{\mathrm{jk}}(\mathrm{u}) \mathrm{du}$

$\left(\pi_{j k}\right.$ are stationary probabilities of the marginal process $\left.\left(Y_{t}, Z_{t}\right)\right)$ we have: 


$$
\mathrm{k} \mu_{\mathrm{j}} \pi_{\mathrm{jk}}=(\mathrm{k}+1) \mu_{\mathrm{j}} \pi_{\mathrm{k}, \mathrm{k}+1}-\pi_{\mathrm{jk}}(0), 0 \leq \mathrm{k} \leq(\mathrm{j}, \mathrm{m}-1), 0 \leq \mathrm{j} \leq \mathrm{m},
$$

$$
\mathrm{k} \mu_{\mathrm{k}-1} \pi_{\mathrm{k}-1, \mathrm{k}}=\pi_{\mathrm{k}-1}(0)-\pi_{\mathrm{k}-1, \mathrm{k}}(0), \mathrm{j}=\mathrm{k}-1,1 \leq \mathrm{k} \leq \mathrm{m},
$$

$$
\mathrm{m} \mu_{\mathrm{m}} \pi_{\mathrm{mm}}=\pi_{\mathrm{m}}(0)-\pi_{\mathrm{mm}}(0), \mathrm{k}=\mathrm{j}=\mathrm{m} .
$$

Observing that $\pi_{\mathrm{k}}=\sum_{\mathrm{j}=\mathrm{k}-1}^{\mathrm{m}} \pi_{\mathrm{jk}}$ we obtain from (4.9-4.11) by elementary transformations

$$
n \pi_{n}=\sum_{k=0}^{n-1} \sum_{j=k-1}^{m} \frac{1}{\mu_{j}} \pi_{j k}(0)-\sum_{k=1}^{n-1} \frac{1}{\mu_{k-1}} \pi_{k-1}(0), n=1, \ldots, m
$$

$$
\pi_{0}=1-\sum_{\mathrm{n}=1}^{\mathrm{m}} \pi_{\mathrm{n}}
$$

From (4.11) and (4.10) (for $\mathrm{k}=\mathrm{m})$ we also derive

$$
\mathrm{m} \pi_{\mathrm{m}}=\frac{1}{\mu_{\mathrm{m}}}\left[\pi_{\mathrm{m}}(0)-\pi_{\mathrm{mm}}(0)\right]+\frac{1}{\mu_{\mathrm{m}-1}}\left[\pi_{\mathrm{m}-1}(0)-\pi_{\mathrm{m}-1, \mathrm{~m}}(0)\right] .
$$

It can easily be shown that (4.14) and (4.12) for $\mathrm{n}=\mathrm{m}$ coincide.

To find the unknown probabilities $\pi_{\mathrm{jk}}(0)$ and $\pi_{\mathrm{k}}(0)$ we apply a method similar to that developed by Dshalalow [2]. In this case we treat $\left(\mathrm{Y}_{\mathrm{t}}, \mathrm{Z}_{\mathrm{t}}, \mathrm{V}_{\mathrm{t}}\right)$ as a semi-regenerative process relative to $\left(T_{n}\right)$. It enables to apply the main convergence theorem to the transition function $\mathrm{P}_{\mathrm{t}}(\mathrm{i}, \mathrm{B})$ (see Theorem A.2, Appendix) by taking for

$$
\mathrm{B}=\{\mathrm{k}, \mathrm{n}\} \times[0, \mathrm{y}], \mathrm{k}, \mathrm{n} \in \mathrm{E}, \mathrm{y} \in \mathbb{R}_{+} .
$$

Let $\mathrm{p}_{\mathrm{jk}}(\mathrm{t}):=\mathrm{P}^{\mathrm{j}}\left\{\mathrm{Z}_{\mathrm{t}}=\mathrm{k} \mid \mathrm{T}_{1}>\mathrm{t}\right\}$. Making use of the obvious assumptions that $\mathrm{P}^{\mathrm{j}}\left\{\mathrm{Z}_{\mathrm{t}}=\mathrm{k} \mid \mathrm{T}_{1}>\mathrm{t}+\mathrm{y}\right\}=\mathrm{p}_{\mathrm{jk}}(\mathrm{t}), \forall \mathrm{y} \geq 0$, we then deduce by simple probability arguments that

$$
\begin{array}{r}
\mathrm{K}_{\mathrm{t}}^{\mathrm{j}}(\{\mathrm{k}, \mathrm{n}\} \times[0, y])=\delta_{\mathrm{j}, \mathrm{n}} \mathrm{p}_{\mathrm{jk}}(\mathrm{t})\left[\mathrm{A}_{\mathrm{j}}(\mathrm{t}+\mathrm{y})-\mathrm{A}_{\mathrm{j}}(\mathrm{t})\right] \\
\left(\delta_{\mathrm{j}, \mathrm{n}}\right. \text { is Kronecker delta). }
\end{array}
$$

Observing that $\int_{\mathbb{R}_{+}} p_{j k}(t) A_{j}(d t)=p_{j k}, j, k \in E$, are transition probabilities of the embedded $\mathrm{MC}\left(\mathrm{X}_{\mathrm{n}}\right)$ we see that

$$
t \rightarrow p_{j k}(t)\left[A_{j}(t+y)-A_{j}(t)\right]
$$

is directly integrable. Thus by Theorem A.2 and due to (4.15) we obtain 
(4.16) $\lim _{t \rightarrow \infty} P^{i}\left\{Y_{t}=j, Z_{t}=k, V_{t} \leq y\right\}=\frac{P_{j}}{P A} \int_{\mathbb{R}_{+}} p_{j k}(t)\left[A_{j}(t+y)-A_{j}(t)\right] d t, j, k \in E, y \in \mathbb{R}_{+}$.

Denoting

$$
g_{j k}(x):=\frac{P_{j}}{P A} \int_{\mathbb{R}_{+}} p_{j k}(t) a_{j}(t+x) d t, x \in \mathbb{R}_{+},
$$

we have by Fubini's theorem

$$
\int_{[0, y]} g_{j k}(x) d x=\frac{P_{j}}{P A} \int_{\mathbb{R}_{+}} p_{j k}(t)\left[A_{j}(t+y)-A_{j}(t)\right] d t, j, k \in E, y \in \mathbb{R}_{+} .
$$

By virtue of the same arguments as for process $\left(Z_{t}\right)$ and its limiting distribution $\pi_{k}$ we have for semi-regenerative process $\left(Z_{t}, V_{t}\right)$ the existance of

$$
\pi_{\mathrm{jk}}(\mathrm{x})=\lim _{\mathrm{t} \rightarrow \infty} \pi_{\mathrm{jk}}(\mathrm{x}, \mathrm{t})
$$

Now by setting

$$
\lim _{\mathrm{y} \rightarrow 0} \lim _{\mathrm{t} \rightarrow \infty} \pi_{\mathrm{jk}}(\mathrm{y}, \mathrm{t})=\lim _{\mathrm{t} \rightarrow \infty} \lim _{\mathrm{y} \rightarrow 0} \pi_{\mathrm{jk}}(\mathrm{y}, \mathrm{t})
$$

we obtain from (4.16) and (4.17)

$$
\lim _{\mathrm{t} \rightarrow \infty} \int_{[0, \mathrm{y}]} \pi_{\mathrm{jk}}(\mathrm{y}, \mathrm{t}) \mathrm{du}=\int_{[0, \mathrm{y}]} \mathrm{g}_{\mathrm{jk}}(\mathrm{u}) \mathrm{du}, \mathrm{y} \in \mathbb{R}_{+} .
$$

By the mean value theorem and in view of (4.16) and (4.18) we have

$$
\pi_{j k}(0)=g_{j k}(0)=\frac{P_{j}}{P A} \int_{\mathbb{R}_{+}} p_{j k}(t) a_{j}(t) d t=\frac{P_{j}}{P A} p_{j k}, j, k \in E,
$$

that specifically yields

$$
\pi_{\mathrm{k}}(0)=\sum_{\mathrm{j}=\mathrm{k}-1}^{\mathrm{m}} \pi_{\mathrm{jk}}(0)=\frac{\mathrm{P}_{\mathrm{k}}}{\mathrm{PA}}, \mathrm{k} \in \mathrm{E} .
$$

The latter enables to obtain $\pi_{\mathrm{n}}$ explicitly from (4.12) and (4.13) in form of the expressions (4.1) and (4.2). The proof of the theorem is therefore completed.

4.2 Remark. For $\mu_{\mathrm{j}} \equiv \mu, \mathrm{j} \in \mathrm{E}$, we obtain a compact formula for $\pi_{\mathrm{n}}$ :

$$
\begin{gathered}
\mu P A n \pi_{n}=\sum_{k=0}^{n-1} P_{k}-\sum_{k=1}^{n-1} P_{k-1}=P_{n-1}, n=1, \ldots, m . \\
\mu P A \pi_{0}=\sum_{n=1}^{m} n P_{n-1} .
\end{gathered}
$$


The well-known Takács' formula [3] follows from (4.12), (4.22) if we set $\mathrm{a}_{0}=\mathrm{a}_{1} \ldots=\mathrm{a}_{\mathrm{m}}=\mathrm{a}$ (in this case PA $=1$ ):

$$
\pi_{\mathrm{n}}=\frac{1}{\mu \mathrm{n}} \mathrm{P}_{\mathrm{n}-1}, \mathrm{n}=1, \ldots, \mathrm{m} .
$$

We allow also in this case $A_{j}(x)$ to be arbitrary but with the expectation equals a for all $\mathrm{j}=0,1, \ldots, \mathrm{m}$.

(4.21) implies an elegant formula for the average number of busy storage units $\mathrm{Z}$ in the steady state:

$$
E[Z]=\frac{1}{\mu \mathbf{P A}} \sum_{i=1}^{m} P_{i-1}
$$

4.3 Example. We here consider an approach appropriate for solving of many optimizations problems occuring in queueing, reliability theory, inventory and, specifically suitable for our transportation problem.

Let $\mathscr{A}$ be the set of all acts available. Each of these acts is identified with a choice of delivery type (i.e. a choice of transport and a choice of a route) and a choice of storage rate. $T_{0}, T_{1}, \ldots$ are decision points, i.e. when the process $\left(Z_{t}\right)$ is at time point $T_{n}-0$ in a state $\mathrm{j} \in \mathrm{E}$, then an act $a_{\mathrm{n}}(\mathrm{j}) \in \mathscr{A}$ is chosen. The DF of $\mathrm{T}_{\mathrm{n}+1}-\mathrm{T}_{\mathrm{n}}$ and the DF of the storage durations of all goods in the time interval $\left[T_{n}, T_{n+1}\right)$ depends on $a_{n}(j)$. The sequence $a_{0}, a_{1}, \ldots$ of acts chosen at each decision point determines a stationary strategy $\mathscr{S}$. Let $\mathscr{S}_{\mathrm{t}}$ be the corresponding sequence of acts chosen at decision points $\mathrm{T}_{0}, \mathrm{~T}_{1}, \ldots, \mathrm{T}_{\mathrm{N}_{\mathrm{t}}}$, and let $\mathrm{C}\left(\mathscr{S}_{\mathrm{t}}\right)$ be the expected reward of the strategy $\mathscr{S}_{\mathrm{t}}$. Then

$$
\mathrm{C}(\mathscr{S})=\lim _{\mathrm{t} \rightarrow \infty} \frac{1}{\mathrm{t}} \mathrm{C}(\mathscr{S})
$$

is the total profit rate of the strategy $\mathscr{S}$. We specify $\mathrm{C}$ as follows:

Let $H_{r}, r=1,2,3,4$, be $\mathbb{R}$-valued bounded functions defined on $\mathbb{N}_{0}$, such that $\mathrm{H}_{1}(\mathrm{i})$ denotes the expences of the storing of $\mathrm{i}$ units per unit time;

$\mathrm{H}_{2}(\mathrm{j})$ denotes the transportation costs per unit time in accordance with the act $a_{\mathrm{n}}(\mathrm{j})$; $\mathrm{H}_{3}$ (const.) denotes the reward for each stored unit of goods;

$\mathrm{H}_{4}$ (const.) is penalty set for each lost customer.

Let us define the functionals

$\mathrm{U}_{1} \mathrm{H}_{\mathrm{r}}(\mathrm{i}, \mathrm{t}):=\mathrm{E}^{\mathrm{i}}\left[\int_{0}^{\mathrm{t}} \mathrm{H}_{\mathrm{r}}\left(\mathrm{Z}_{\mathrm{u}}\right) \mathrm{du}\right], \mathrm{U}_{2} \mathrm{H}_{\mathrm{r}}(\mathrm{i}, \mathrm{t}):=\mathrm{E}^{\mathrm{i}}\left[\int_{0}^{\mathrm{t}} \mathrm{H}_{\mathrm{r}}\left(\mathrm{Y}_{\mathrm{u}}\right) \mathrm{du}\right], \mathrm{r}=1,2,3,4$,

and Markov renewal function 


$$
R_{t}(i, j):=E^{i}\left[\sum_{n=0}^{\infty} I_{j} \circ X_{n} \cdot I_{[0, t]} \circ T_{n}\right]
$$

giving the expected number of entrances of the embedded $M C\left(X_{n}\right)$ in the state $\{j\}$ within the time interval $[0, t]$. For example, $R_{t}(i, m)$ is the expected number of losses during the time $[0, t]$. Denoting by

$$
R_{t}(i):=\sum_{j=0}^{\infty} R_{t}(i, j)
$$

we obtain the expected number of units of goods delivered and then being processed until the time $t$ :

$$
R_{t}(i)-R_{t}(i, m)-E^{i}\left[Z_{t}\right] .
$$

The total expected income of the system in the time interval $[0, t]$ with the given initial state $\{\mathrm{i}\}$ of the process $\left(\mathrm{Z}_{t}\right)$ is

$$
\left.\mathrm{C}\left(\mathscr{S}_{\mathrm{t}}\right)=\mathrm{U}_{1} \mathrm{H}_{1}(\mathrm{i}, \mathrm{t})+\mathrm{U}_{2} \mathrm{H}_{2}(\mathrm{i}, \mathrm{t})+\mathrm{H}_{3} \mathrm{R}_{\mathrm{t}}(\mathrm{i})-\mathrm{R}_{\mathrm{t}}(\mathrm{i}, \mathrm{m})-\mathrm{E}^{\mathrm{i}}\left[\mathrm{Z}_{\mathrm{t}}\right]\right)-\mathrm{H}_{4} \mathrm{R}_{\mathrm{t}}(\mathrm{i}, \mathrm{m}) .
$$

Therefore, the total income rate of the strategy $\mathscr{S}$ is determined by

$$
\begin{aligned}
C(\mathscr{S}) & =\lim _{t \rightarrow \infty} \frac{1}{t}\left[U_{1} H_{1}(i, t)+U_{2} H_{2}(i, t)+H_{3}\left(R_{t}(i)-R_{t}(i, m)-E^{i}\left[Z_{t}\right]\right)-H_{4} R_{t}(i, m)\right] \\
& =\lim _{t \rightarrow \infty} \frac{1}{t}\left[U_{1} H_{1}(i, t)+U_{2} H_{2}(i, t)+H_{3} R_{t}(i)-\left(H_{3}+H_{4}\right) R_{t}(i, m)\right] .
\end{aligned}
$$

The optimization problem can be formulated as follows: Among the set $\Pi$ of all admissible strategies find a strategy $\mathscr{S}^{0} \in \Pi$ such that

$$
\mathrm{C}\left(\mathscr{S}^{0}\right)=\sup \{\mathrm{C}(\mathscr{S}): \mathscr{S} \in \Pi\}
$$

We first calculate $\mathrm{C}(\mathscr{S})$ in (4.23). Using a similar approach as in Dshalalow [2] (p. 422) we obtain

$$
\begin{aligned}
& \lim _{t \rightarrow \infty} \frac{1}{t}\left[U_{1} H_{1}(i, t)+U_{2} H_{2}(i, t)\right] \\
& =\sum_{n \in E}\left[H_{1}(n) \pi_{n}+H_{2}(n) \frac{P_{n} a_{n}}{P A}\right] .
\end{aligned}
$$

Since $\lim _{t \rightarrow \infty} \frac{1}{t} R_{t}(i, j)=\frac{P_{j}}{P A}$ (see for instance, Çinlar [1], p. 329) we finally have 
$\mathrm{C}(\mathscr{S})=\sum_{\mathrm{n} \in \mathrm{E}}\left[\mathrm{H}_{1}(\mathrm{n}) \pi_{\mathrm{n}}+\mathrm{H}_{2}(\mathrm{n}) \frac{\mathrm{P}_{\mathrm{n}} \mathrm{a}_{\mathrm{n}}}{\mathbf{P A}}\right]+\mathrm{H}_{3} \frac{1}{\mathbf{P A}}-\left(\mathrm{H}_{3}+\mathrm{H}_{4}\right) \frac{\mathrm{P}_{\mathrm{m}}}{\mathbf{P A}}$

Therefore, $\mathbf{C}$ is a function only of $\boldsymbol{\pi}, \mathbf{P}, \mathbf{A}$ and $\boldsymbol{\mu}=\left(\mu_{0}, \mu_{1}, \ldots, \mu_{\mathrm{m}}\right)$.

Now if we wish to use the explicit formulas for $\mathbf{P}$ derived in Section 3, we can formulate the optimization problem (4.24) for this special case as follows:

Determine positive integers $k$ and $s(0 \leq k \leq s \leq m)$, choose $A_{k}(x), A_{s}(x), A(x)$ from a given set of distribution functions and choose $\mu_{\mathrm{k}}, \mu_{\mathrm{s}}, \mu$ from a given set of positive real numbers maximazing the objective function $\mathrm{C}$.

\section{APPENDIX}

\section{A.1 Definition. A separable stochastic process}

$\left(\Omega, A,\left(\mathrm{P}^{\mathrm{x}}\right)_{\mathrm{x} \in \mathrm{E}},\left(\mathrm{Z}_{\mathrm{t}}: \mathrm{t} \geq 0\right) \rightarrow(\mathscr{E}, \mathscr{B}(\mathscr{E}))\right.$ is said to be semi-regenerative, if

1) there exists a Markov renewal process $\left(X_{n}, T_{n}\right)$, such that the state space $E$ of $\left(X_{n}\right)$ is at most countably infinite,

2) $T_{0}, T_{1}, \ldots$ is a sequence of stopping times relative to the canonical filtering $\sigma\left(Z_{\mathrm{u}} ; \mathrm{u} \leq \mathrm{t}\right)$

3) for each $\mathrm{n} \in \mathbb{N}_{0} \mathrm{X}_{\mathrm{n}}$ is $\mathscr{A}_{\mathrm{T}_{\mathrm{n}}}$-measurable $\left(\mathscr{A}_{\mathrm{T}_{\mathrm{n}}}\right.$ is $\mathrm{T}_{\mathrm{n}}$-past $\sigma$-algebra),

4) for each bounded random variable $\psi: \Omega \rightarrow \mathscr{E} \mathrm{r}$ and for each Baire function $\mathrm{f}: \mathscr{E} \mathrm{r} \rightarrow \mathbb{R}(\mathrm{r}=1,2, \ldots)$ the following expression holds:

$\mathrm{E}^{\mathrm{x}}\left[\mathrm{f} \circ \psi \circ \theta_{\mathrm{T}_{\mathrm{n}}} \mid \mathscr{A}_{\mathrm{T}_{\mathrm{n}}}\right]=\mathrm{E}^{\mathrm{X}_{\mathrm{n}}}[\mathrm{f} \circ \psi] \mathrm{P}^{\mathrm{x}}$ - a.s., provided that $\psi \circ \theta_{\mathrm{T}_{\mathrm{n}}}$ is $\mathscr{A}$-measurable $\left(\theta_{\mathrm{u}}\right.$ is the shift operator), $\mathrm{n}=0,1, \ldots$

A.2 Theorem. (cf., Çinlar [2], p.347). Let $\left(\Omega, A,\left(\mathrm{P}^{\mathrm{x}}\right)_{\mathrm{x} \in \mathrm{E}},\left(\mathrm{Z}_{\mathrm{t}} ; \mathrm{t} \geq 0\right)\right) \rightarrow(\mathscr{E}, \mathscr{B}(\mathscr{E}))$ be a semi-regenerative process, and let $\left(\mathrm{X}_{\mathrm{n}}, \mathrm{T}_{\mathrm{n}}\right)$ be irreducible, aperiodic and recurrentpositive. Let $\mathbf{P}$ denote the invariant probability measure of $\left(X_{n}\right)$ and $\mathrm{K}_{\mathrm{t}}^{\mathrm{i}}(\mathrm{B}):=\mathrm{P}^{\mathrm{i}}\left\{\mathrm{Z}_{\mathrm{t}} \in \mathrm{B}, \mathrm{T}_{1}>\mathrm{t}\right\}, \mathrm{i} \in \mathrm{E}, \mathrm{B} \in \mathscr{B}(\mathscr{\mathscr { C }})$. Suppose that $\mathrm{t} \rightarrow \mathrm{K}_{\mathrm{t}}^{\mathrm{i}}(\mathrm{B})$ is directly integrable over $\mathbb{R}_{+}$. Then $\lim _{\mathrm{t} \rightarrow \infty} \mathrm{P}_{\mathrm{t}}(\mathrm{i}, \mathrm{B})=\lim _{\mathrm{t} \rightarrow \infty} \mathrm{P}^{\mathrm{i}}\left\{\mathrm{Z}_{\mathrm{t}} \in \mathrm{B}\right\}$ exists, is independent of $\mathrm{i}$ and is a probability measure on $(\mathscr{E}, \mathscr{B}(\mathscr{E}))$. Besides, the following expression holds: 


$$
\lim _{t \rightarrow \infty} P_{t}(i, B)=\frac{1}{\mathbf{P A}} \sum_{j \in E} P_{j} \int_{\mathbb{R}_{+}} K_{t}^{j}(B) d t,
$$

where $\mathbf{A}:=\left(\mathrm{a}_{0}, \mathrm{a}_{1}, \ldots \mathrm{a}_{\mathrm{m}}\right)^{\mathrm{T}}, \mathrm{a}_{\mathrm{r}}:=\mathrm{E}^{\mathrm{r}}\left[\mathrm{T}_{1}\right], \mathrm{r} \in \mathrm{E}$.

\section{REFERENCES}

[1]. Çinlar, E., Introduction to Stochastic Processes, Prentice Hall, Englewood Cliffs, New Jersey, 1975.

[2]. Dshalalow, J., On the Multiserver Queue with Finite Waiting Room and Controlled Input, Adv. Appl. Prob. 17, 408-423, 1985.

[3]. Takács, L., Introduction to the Theory of Queues, Oxford University Press, New York, 1962. 


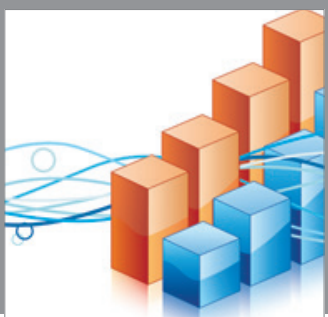

Advances in

Operations Research

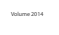

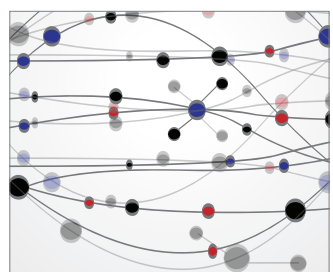

\section{The Scientific} World Journal
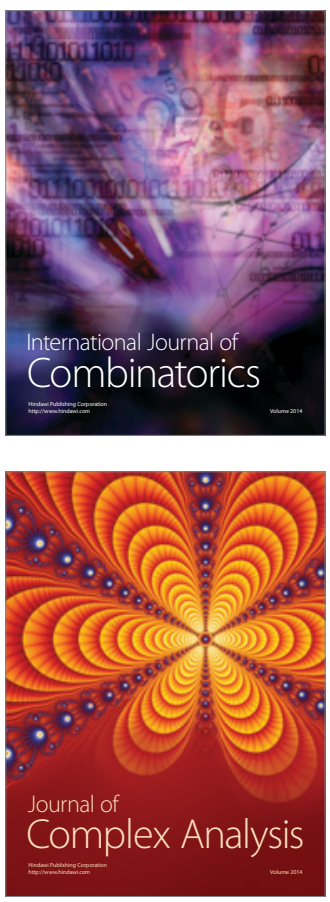

International Journal of

Mathematics and

Mathematical

Sciences
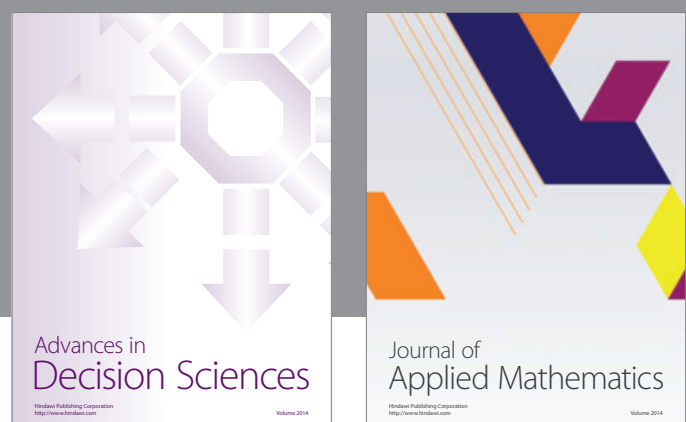

Journal of

Applied Mathematics
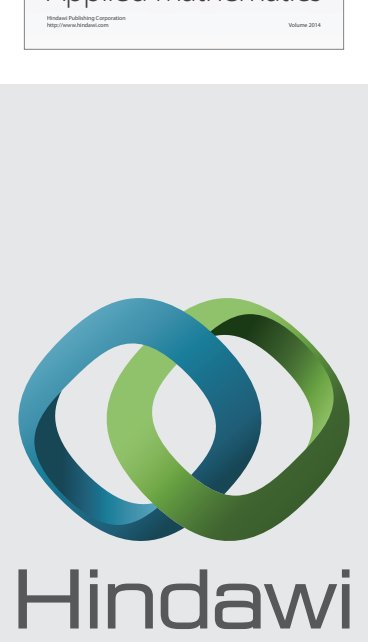

Submit your manuscripts at http://www.hindawi.com
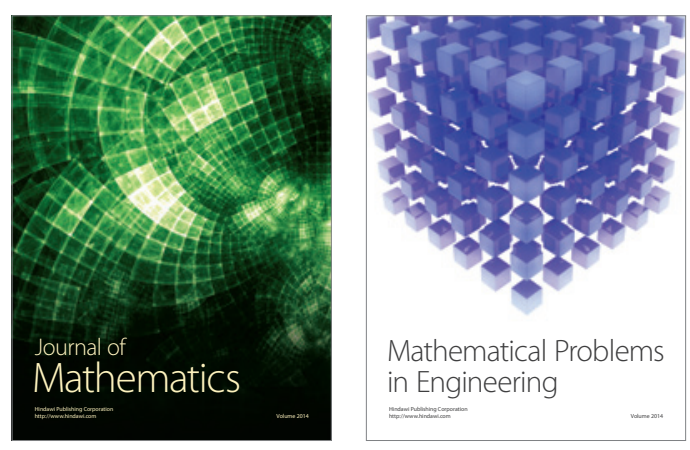

Mathematical Problems in Engineering
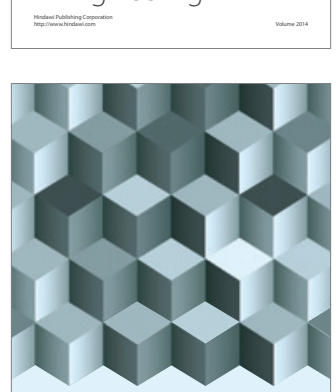

Journal of

Function Spaces
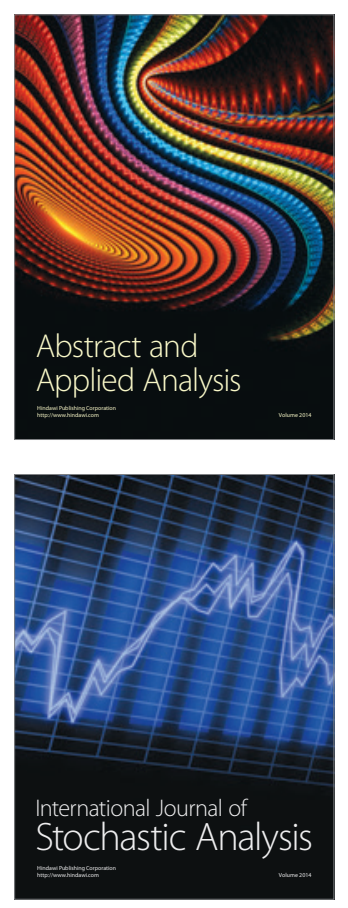

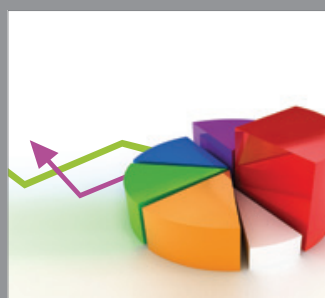

ournal of

Probability and Statistics

Promensencen
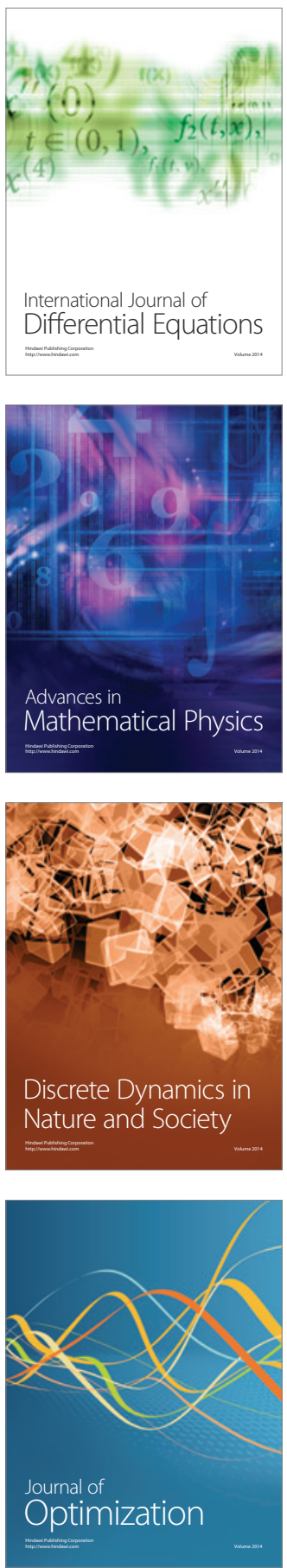